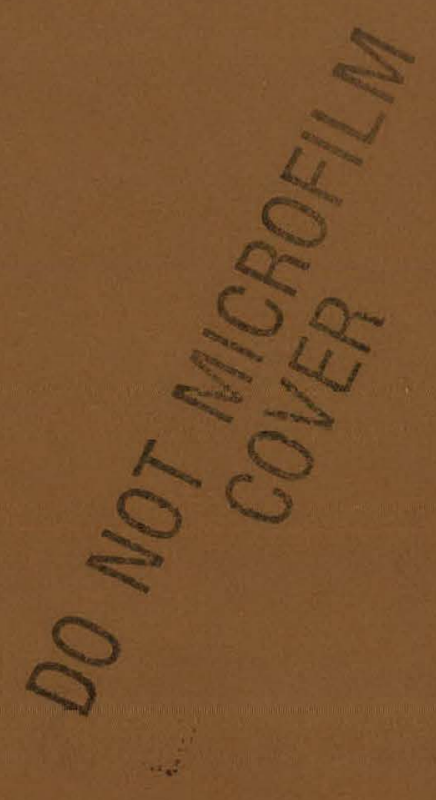

An International Research
Laboratory on the Moon:
A Proposal for a National Commitment 


\section{DISCLAIMER}

This report was prepared as an account of work sponsored by an agency of the United States Government. Neither the United States Government nor any agency Thereof, nor any of their employees, makes any warranty, express or implied, or assumes any legal liability or responsibility for the accuracy, completeness, or usefulness of any information, apparatus, product, or process disclosed, or represents that its use would not infringe privately owned rights. Reference herein to any specific commercial product, process, or service by trade name, trademark, manufacturer, or otherwise does not necessarily constitute or imply its endorsement, recommendation, or favoring by the United States Government or any agency thereof. The views and opinions of authors expressed herein do not necessarily state or reflect those of the United States Government or any agency thereof. 


\section{DISCLAIMER}

Portions of this document may be illegible in electronic image products. Images are produced from the best available original document. 
Edited by Elaine Stanlick

Photocomposition by Jo Ann Painter

DISCLAIMER

This report was prepared as an account of work sponsored by an agency of the United States Government. Neither the United States Government nor any agency thereof, nor any of their employees, makes any warranty, express or implied, or assumes any legal liability or responsibility for the accuracy, completeness, or usefulness of any information, apparatus, product, or process disclosed, or represents that its use would not infringe privately owned rights. References herein to any specific commercial product, process, or service by trade name, trademark, manufacturer, or otherwise, does not necessarily constitute or imply its endorsement, recommendation, or favoring by the United States Government or any agency thereof. The views and opinions of authors expressed herein do not necessarily state or reflect those of the United States Government or any agency thereof. 


\section{An International Research Laboratory on the Moon: A Proposal for a National Commitment}

Paul W. Keaton

Eric M. Gelfand

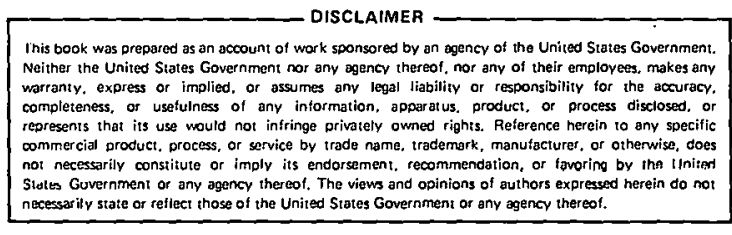




\section{PAGES ii to iii WERE INTENTIONALLY LEFT BLANK}




\section{CONTENTS}

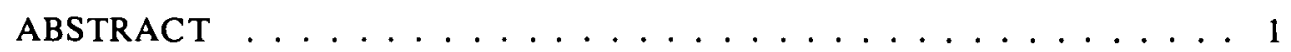

I. INTRODUCTION $\ldots \ldots \ldots \ldots \ldots \ldots \ldots \ldots$

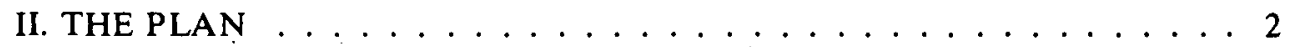

III. SCIENTIFIC BENEFITS $\ldots \ldots \ldots \ldots \ldots$

IV. ECONOMIC BENEFITS $\ldots \ldots \ldots \ldots \ldots \ldots \ldots$

V. POLITICAL BENEFITS $\ldots \ldots \ldots \ldots \ldots$

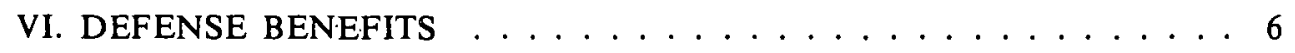

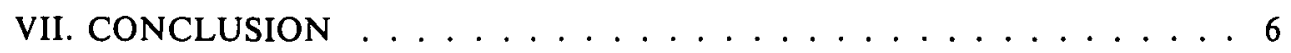

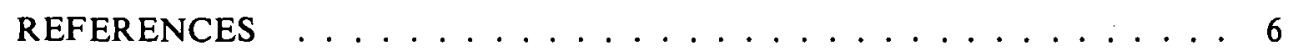

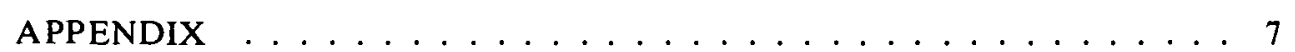




\title{
AN INTERNATIONAL RESEARCH LABORATORY ON THE MOON: A PROPOSAL FOR A NATIONAL COMMITMENT
}

\author{
by
}

Paul W. Keaton and Eric M. Gelfand

\begin{abstract}
To demonstrate its leadership in space, the US could focus its space program on an exciting and achievable goal: to establish a self-sustaining international research laboratory on the Moon before the year 2000. Scientists from all over the world would use the laboratory for basic and applied programs in natural and social sciences. The knowledge gained would benefit everyone.

The lunar research facility would be built with a broadly based infrastructure of stations, vehicles, and programs that can be envisioned as a pyramid resting on the Earth and reaching to the Moon. The first element of the infrastructure is the reusable Space Shuttle; the second is a manned low-Earth-orbit platform. Next is an orbital transfer vehicle for hauling cargoes between low Earth orbit and low lunar orbit. The final element is the manned self-sustaining international research laboratory.

A key feature of this proposal is that each element can be economically useful at the same time as it is promoting international cooperation on Earth. A vigorous civilian program like that proposed here is our best guarantee that outer space will be used to strengthen our economy and address basic problems on Earth.
\end{abstract}

\section{INTRODUCTION}

The world will reap abundant economic and scientific benefits when we learn to control the forces of nature in the extraterrestrial environment. The United States could help the world to realize these benefits by focusing its own space program for the next two decades on an exciting and achievable goal if the President would announce that the United States will establish a self-sustaining international research laboratory on the Moon before the year 2000. Scientists of every nation could use this laboratory to study - in ways we cannot here-physical phenomena that shape our lives. The knowledge gained would be used for the benefit of all peoples of the Earth.
In June 1981, President Reagan asked the Office of Science and Technology Policy, directed by the Science Advisor Dr. George Keyworth, to review our Nation's space program. Indicating "considerable concern in the Administration on the future directions of the space program," Keyworth said that his study should influence the national space fiscal year 1983 budget, and that it will look into both civilian and defense aspects. ${ }^{1}$ We realize this is a poor time for new initiatives but it is a particularly important time for scientists to discuss this Nation's future space role in an open forum. Our hope is that a consensus will emerge as the economy recovers.

A recurring theme of the US debate on space programs concerns the relative merits of exploration vs 
exploitation in space. It need not be a choice of one at the expense of the other. A combination of exploration and exploitation programs would gain greater support from the public and yield higher payoff to the economy than would be derived from the sum of separate programs. However, this balanced set of programs requires the commitment to station people in space.

This commitment has already been made by another nation. Last July, the Soviet Union achieved another space sensation by automatically docking the Cosmos 1267 spacecraft to the Solyut- 6 space laboratory, nearly doubling the size of the station. Having cleared the way for new Russian manned space initiatives, Soviet President Leonid Brezhnev announced, "We are now ready to take the next step to [move] to the creation of permanent orbital complexes with changeable crews."2 The Soviet Union is the first country to announce this commitment but it seems reasonable to assume that others will follow.

The United States has developed the Space Shuttle, which will reduce the cost of putting things into low Earth orbit. In terms of energy expenditure, low Earth. orbit is about half-way to geosynchronous orbit, the Moon, and escaping the Earth's gravitational influence. The Shuttle provides an excellent basis for a versatile manned and unmanned US space program.

This proposal integrates the Space Shuttle into an evolutionary plan that establishes a transportation system reaching from the Earth to the Moon. It leaves many options open along the way. It provides opportunities for exploration and exploitation-for national prestige and international cooperation-and for addressing problems on Earth, including those that limit growth. It establishes a framework for the US space program during the next two decades.

\section{THE PLAN}

The lunar research facility would be built with a broadly based infrastructure of stations, vehicles, and programs, which we see as a pyramid resting on the Earth and reaching to the Moon. The first element of the infrastructure, the reusable Space Shuttle, has been developed and was successfully tested in April and November 1981. The next element is a low-Earth-orbit platform. This has also been advocated as the next step to follow the Shuttle by NASA Administrator James Beggs and Deputy Administrator Hans Mark in their confirmation hearings of spring 1981.

The next element would be development of orbital transfer vehicles for hauling cargoes between low Earth orbit and low lunar orbit. Then it may be useful to develop a low-lunar-orbit platform. The final element would be to build and man the self-sustaining international research laboratory in phases over several years. Each element of the architecture can be used for economic and scientific exploitation and, at the same time, foster international cooperation on Earth.

By 2000 , the laboratory would be a valuable asset for basic and applied sciences programs in natural and social sciences. After that, the knowledge gained could provide ways to use the Moon's resources and environment. It could become a basis for an infrastructure that can be envisioned as an inverted pyramid that is based on the Moon and reaches back toward Earth, bringing new economic benefits. It could also be used as a springboard for unmanned deep space probes and establishment of large space settlements. ${ }^{3}$ The many possibilities that would be opened are well beyond the scope of this proposal.

The international nature of this project must be studied carefully. Two models are suggested by analogy with the CERN and Fermilab large-particle accelerator laboratories. CERN (Geneva, Switzerland) was built and is managed by representatives from several countries: Fermilab (Chicago) was built and is managed by one country. Both laboratories are "international" and accept research scientists from all over the world. Pending further study, we assume the Fermilab model for the Moon laboratory.

Costs of placing a research laboratory on the Moon (but not of developing the infrastructure) can be put in perspective by citing a Stanford-Ames study conducted in the summer of $1968 .^{4}$ The study, called Moonlab, addressed the technical and funding aspects of placing a partially self-sustaining ' research laboratory weighing 276 tons and housing 24 people on the Moon. They concluded that over a 15 -year period, the total development, acquisition, delivery, and building costs would be $\$ 17.4$ billion. That can be compared directly with the $\$ 25$ billion spent in the 1960s on the Apollo program to place a man on the Moon. In 1982 dollars, the \$17.4 billion would be inflated to about $\$ 50$ billion, which would be spent over 18 years. For comparison, $\$ 80$ billion is about $0.1 \%$ of the cumulative US Gross National Product (GNP) between 1982 and 2000.

\section{SCIENTIFIC BENEFITS}

The Moon is a focus for comparative planetological studies because it is exceptionally volatile-poor. It 
evolved without a major atmosphere or water. In situ examinations could lead to interactive and follow-on capabilities, which are invaluable in conducting substantial scientific investigation. Studying the Moon will provide a greater understanding of the Earth and its resources.

Less than $4 \%$ as much energy is required for an object to escape from the surface of the Moon as from the surface of the Earth. A self-sufficient lunar facility could serve as an oasis, a hospital, a springboard into deep space, or simply a resting station for scientists/astronauts of any nationality whose mission calls for prolonged stays in cislunar space.

The laboratory could offer refuge from solar flare radiation to astronauts outside the Earth's magnetic field. Solar flares have been studied continually since the International Geophysical Year (IGY) of 1957. During and shortly after the IGY, 30 solar flares were observed, 6 intense enough to kill an astronaut protected only by a space suit. Radioactivity from a giant solar flare could even endanger astronauts in a spacecraft unless they are well shielded. All US manned space missions (Gemini, Apollo, Skylab, and Apollo-Soyuz) were scheduled for times when no solar flares werc forecast. ${ }^{3}$ A lunar research facility can provide safe areas shielded from radiation by raising large piles of dirt (one-sixth as heavy as on Earth) on top of housing quarters. In addition, bulk shielding (dirt) can be moved into space to protect spacecraft.

Many investigations that relate to processes in an extraterrestrial environment cannot be addressed in a laboratory on Earth. Examples are the easy access to extreme vacuum and the interference-free reception of all radio frequencies. The Moon's weak gravity $(1 / 6 \mathrm{~g})$ and negligible magnetic field (tens of microgauss) would also be advantageous in many experiments and would allow new investigations in both basic and applied sciences.

Studies of the basic sciences would include experiments to test the basic physical laws of nature as well as to expand the frontiers of modern chemistry, biology, astronomy, cosmology, and particle physics. New levels of purity, high vacuum, and direct access to space suggest the possibilities of exciting new discoveries and fundamental experiments.

Studies of the applied sciences would be enhanced in the Moon's cnvironment. A large technology base would be assembled just to design and engineer the lunar research facility itself. For example, energy sources. would be developed, oxygen and minerals would be extracted from the soil, agronomy would be advanced, and materials sciences would develop new techniques. Many spin-off benefits have been accrued by the US economy from large space programs.

In addition to the natural sciences, the Moon laboratory will stimulate relevant studies in the social sciences. By creating a microcosm of the Earth, advances in economics, political science, and sociology will be made. The coupling of technical and social sciences into an entirely closed system will advance knowledge in such problem areas as ecology, waste management, and the behavioral sciences. The research and support facility will be an exciting experiment in itself, seeking knowledge of how to manage our total environment on Earth.

Once the US is committed to a lunar research laboratory, we expect that many previously undecided young people will choose a science career. More important, "adventures in space" is the one subject in science that has a powerful grip on the imagination of people of every economic background. This entire enterprise could provide a rapid increase in scientific and engineering manpower to increase our Nation's productivity.

\section{ECONOMIC BENEFITS}

The first commercial communications test satellite, Telstar I, was put into orbit on July 10, 1962. American Telephone and Telegraph built Telstar I and funded NASA to launch it. Subsequently, the Communications Satellite Corporation (COMSAT) was formed to operate satellites as a privately owned corporation regulated by the Government. In 1970, the COMSAT Board of Directors declared a dividend-the first money made by the general public for a space venture. COMSAT is now the managing agent of Intelsat, a 105-nation consortium. Today, companies like COMSAT and Intelsat are doing over $\$ 1$ billion worth of business per year by operating communications satellites. This is about $20 \%$ of NASA's entire budget.

The profitable use of space for the benefit of the entire world is a fait accompli. An integral part of this proposal is that private entrepreneurs would be encouraged to search for sources of revenue-generating products and services in the extraterrestrial environment. At the same time, their costs of getting there would be only incremental because the vehicles would already be developed.

The profit motive is an effective and efficient mechanism for opening a new frontier. The historians Will and Ariel Durant wrote:

The experience of the past leaves little doubt that every economic system must sooner or later rely upon some 
form of the profit motive to stir individuals and groups to productivity. Substitutes like slavery, police supervision, or ideological enthusiasm prove too unproductive, too expensive, or too transient. Normally and generally men are judged by their ability to produce...

But the right to use the profit motive to benefit all mankind cannot be taken for granted. In the case of the Moon, some feel it was almost lost.

Article XI of the United Nations "Moon Treaty" (official title: Agreement Governing the Activities of States on the Moon and Other Celestial Bodies) states:

The Moon and its natural resources are the common heritage of mankind which finds its expression in the provisions of this agreement...

In July 1979, the US delegation joined the rest of the UN General Assembly in passing the Moon Treaty unanimously. Some opponents feel that it would strongly discourage private entrepreneurs from risking investments in space. A ground swell of protests within the United States discouraged the ratification of the treaty in its present form by this country. The Treaty still has not been ratified. It may be possible to amend the Moon Treaty to better reflect the interests of the private sector.

The market potential for private enterprise in the communications business is still high. In October 1980, the Office of Science and Technology Policy asked the American Institute of Aeronautics and Astronautics to study the demand for satellite launches between now and the year 2000 . They concluded that a 10 - to 30 -fold increase would take place in communication satellites, as well as in new demands for nonfederal payloads. The demand will far outstrip the planned four-orbiter shuttle fleet even with competition from the Ariane rocket launching system of the European Space Agency.

Space technology has successfully penetrated the communications market and made a profit. Three other potential markets are remote sensing, materials processing, and energy. Remote sensing can be used to observe the Earth and its environments to make more accurate weather forecasts and manage resources. For example, each new weather satellite brings us closer to achieving an accurate 5-day weather forecast capability. When that goal is reached, an estimated savings of $\$ 5.5$ billion a year in agriculture, construction, transportation, recreation, and other industries may be realized. ${ }^{7}$ These savings alone would almost pay for NASA's annual budget.

Materials processing and manufacturing in space appear to be quite promising but more research and development are required. One concern seems to be that the subject attracts space enthusiasts seeking uses of space, rather than people in the private sector seeking solutions to problems. For example, a 1978 committee of the National Academy of Sciences was not impressed with Skylab experiments to grow pure crystals in a low-g environment, saying, "It has been said that better starting material leads to better [electronic] device performance, but most fabrication processes for devices introduce physical and chemical defects far in excess of tho orise orinally present." ${ }^{\prime 8}$ If research and development were made more routine through the infrastructure necessary to establish a lunar research facility, the most appropriate applications of space technology to industry problems could be found quickly.

The Solar Powered Satellite (SPS) suggested in 1968 by Peter Glaser of the Arthur D. Little Corporation has been given serious attention recently in a $\$ 20$ million joint DOE/NASA study. They considered addressing the Nation's energy problems by installing 60 5-gigawatt satellites in geosynchronous orbit around the Earth. This would produce about half the present US electrical generating capacity in narrow beams of microwaves transmitted to Earth receivers. Again, a National Academy of Sciences committee was skeptical of the proposal and recommended against expenditure of research and development funds in the 1980s for the project. With a price tag of $\$ 1300$ billion, it would be the largest single enterprise ever undertaken. Prudence dictates a certain conservatism in this case. However, with frequent access to geosynchronous orbit and the surface of the Moon, a small amount of additional research would reduce risks significantly while making gains in developing SPS technologies and perhaps lowering the costs.

\section{POLITICAL BENEFITS}

As events unfold over the next two decades, the vision of a self-sustaining research facility on the Moon, peopled by an international user's group of scientists, engineers, and technicians, will inspire the world. Cooperation among nations will be encouraged by the two concepts, science and space, that have fostered international efforts in the past. At the same time, the United States would restore its image as a Nation of action rather than reaction.

In 1955, the United States and the Soviet Union each announced its intention to launch scientific satellites as 
part of the IGY. Contact between US and USSR scientists of any discipline was rare before the Soviet launching of Sputnik I in 195.7 and the United States launching of Explorer I in 1958. But as a result, ${ }^{9}$ in 1959, a scientific exchange agreement was signed by the US National Academy of Sciences and the USSR Academy of Sciences. The launching of the space age provided motivation for this interacademy exchange program even though the space programs were in competition. Similarly, lunar exploration could serve as a vehicle for future East-West cooperation by coordinating missions to take maximum advantage of the complementary technological skills of both space programs.

Western Europe and Japan now have their own strong space programs and are in an excellent position to contribute valuable skills to this worldwide enterprise. In addition, a foundation of space science collaboration already exists between our countries. The largest such effort is an orbiting laboratory that will be launched in 1983. In the United States, NASA designed and built the Space Shuttle, a reusable rocket ship that will place massive payloads (about 30 tons) at low cost (about $\$ 1000 / \mathrm{kg}$ ) into low Earth orbit. Simultaneously, the 11-member European Space Agency invested about \$1 billion to design and build Spacelab, a multipurpose laboratory that will fit into the Space Shuttle and be transported into low Earth orbit. An international research laboratory on the Moon would be a logical extension of the Spacelab concept.

Third World countries could also benefit in a "self-help" manner by participating in the lunar laboratory project. All together, the US space program has involved collaboration with about 75 countries. One example of technology transfer from past space programs to a developing country is found in India. Last June, India used the European Space 'Agency's Ariane launch system to orbit the Indian-built 670-kg Apple communications satellite. Indian scientists also had partial success in launching their Rohini RS-D1 satellite with their own SLV-3 rocket launcher from the Sriharikota range in southeast India.

India's Insat-1 multipurpose spacecraft program is looking farther to the future. The Insat network will use several thousand receiving stations for direct-to-viewer television broadcasts. Receivers costing only $\$ 2,000$ to $\$ 4,000$ each can be placed in many remote areas. In a few years, the world's best educational techniques can be available to the smallest villages throughout India's vast countryside. Similar direct and indirect benefits to man- kind will come from international cooperation in future space activities such as the lunar research facility.

Within the United States, the commitment to build an international research laboratory on the Moon can provide a sense of national purpose to its people. Last May, a national survey conducted by Louis Harris and Associates indicated that $63 \%$ of those surveyed wanted the US to furnish the several billion dollars necessary to develop the full potential of the Space Shuttle over the next 10 years. "This current support for spending on the space program is even more significant in view of the current overwhelming preference for cutting federal spending," the Harris survey said, concluding, "The success of the Space Shuttle seems to have begun to rebuild national pride in our technical know-how." 10

There is some evidence that the general public support for US space programs is not just a short-term result of the recent Space Shuttle success. In a survey of 2000 people taken by McNeal in the Chicago metropolitan area in the fall of 1978 (when the manned space program had been in a hiatus for three years following the Apollo-Soyuz link-up), the responders indicated a positive attitude toward the US space program. For example, on a scale of 15 (most negative) to 75 (most positive) with a neutral value of 45 , the general public rated the space program with a $53 .{ }^{11}$

A startling revelation of McNeal's survey is that more than $50 \%$ of the responders thought that the national budget for space activities was $10 \%$ or more of the Federal budget. It was less than $1 \%$. There was a strong correlation between the general attitude of people toward the space program and the fraction of the Federal budget they thought the space budget to be, as shown in Fig. 1. This indicates that although public opinion of the space program is favorable, considerable additional support

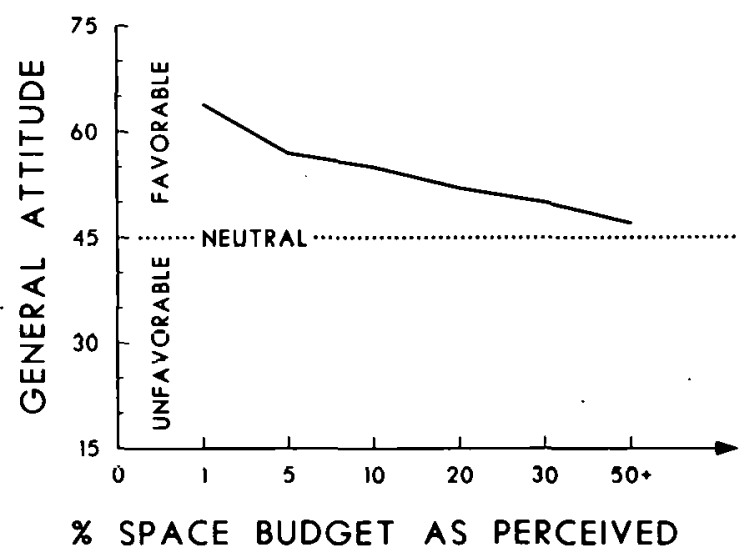

Fig. 1. 
could be gained if the space program were given an understandable goal and the public were educated as to the relatively modest costs involved. Announcing a commitment to place an international research laboratory on the Moon during the next two decades for about $0.1 \%$ of the GNP would satisfy these criteria.

\section{DEFENSE BENEFITS}

The US Department of Defense (DoD) would not receive privileged benefits from the Moon laboratory. Like Fermilab, the international character of the Moon laboratory would give anyone or any nation access to the research results and technology developed there. However, the DoD would use the same low-cost transportation into outer space as private companies or other nations, just as NASA's Space Shuttle will transport both DoD cargoes and the European-built Spacelab into low Earth orbit.

In 1967, the United States, the Soviet Union, and other nations signed and ratified the United Nations' "Outer Space Treaty" (official title: The Treaty on Principles Governing the Activities of States in the Exploration and Use of Outer Space, Including the Moon and Other Celestial Bodies). It declares the Moon a demilitarized area over which no nation may claim sovereignty and it prohibits placing weapons of mass destruction in space. The international research laboratory and its supporting infrastructure are in keeping with the spirit of the Outer Space Treaty.

At the same time, the Moon laboratory will send a clear message to all peoples of the Earth-one that will not require a competing nation to respond by escalating arms.

The major activity of military space flights lies in the area of remote sensing. ${ }^{12}$ Precise information from space about military and related activities all over the world is one of the greatest safeguards against miscalculation by the major powers. In the absence of explicit international agreements for open skies and ground inspection, spy satellites provide the best technique for nonthreatening verification of arms control agreements.

President Johnson made a now famous off-the-record remark in 1967 that the dividends to the United States of military space operations were 10 times the amount spent. This implies that, during the first decade of its existence, the entire US space program paid for itself several times over in terms of defense benefits.

Between 1967 and 1979, 72\% of Soviet launchings were for military purposes as compared to $41 \%$ for the
US. The USSR had 1076 launchings during that period; the US had 404 . Although there will always be pressure in the US to reduce defense expenditures, we will continue to have a military presence in space because verification is the cornerstone of arms control negotiations. But a military presence in space need not mean military dominance of the space program. A vigorous civilian program such as that discussed in this proposal is our best guarantee that the extraterrestrial environment will be used efficiently to strengthen the Nation's economy and benefit all people.

\section{CONCLUSION}

The basic theme of this proposal is that our Nation should demonstrate leadership by picking a long-range goal in space and then developing the infrastructure necessary to achieve that goal. The goal must be chosen so that along the way economic, scientific, political, and defense benefits will pay in dollars as well as in human satisfaction for the effort.

Before a goal will be accepted by the public, it must be technically feasible to the experts, credible to the laymen, affordable to the skeptics, and challenging to the optimists. These are stringent criteria indeed! Few ideas satisfy them all, and even those few are appropriate for only a fleeting moment in history. If the idea is announced too soon-the timid 1970 suggestion that we might place a man on Mars by 1980-it falls flat; if the idea is announced too late-Brezhnev's conservative statement about "permanent orbital complexes with changeable crews"-it stirs little interest. The shining example is our bold commitment in 1961 to place an American on the Moon before 1970.

We believe that the idea of establishing an international lunar research laboratory before the year 2000 fits the necessary criteria for demonstrating leadership today. Few ideas, if any others, do so at this time. We propose that this concept be used to provide an appropriate framework for the United States space program during the next two decades.

\section{REFERENCES}

1. Science 213, 519 (July 31, 1981).

2. See for example Aviat. Week Space Technol., p. 21 (June 29, 1981). 
3. "Space Settlements-A Design Study," National Aeronautics and Space Administration report NASA SP-413 (1977).

4. "Moonlab," Stanford-Ames Faculty Workshop in Engineering Systems Design, June 24-September $6,1968$.

5. Saul J. Adelman and Benjamin Adelman, Bound for the Stars (Prentice-Hall, Inc., New York, 1981), p. 41.

6. Will and Ariel Durant, The Lessons of History (Simon and Schuster, New York, 1968), p. 54.

7. Nation's Business 66, No. 2, 27 (February 1978).
8. See for example T. A. Heppenheimer, Toward Distant Suns (Fawcett Columbine, New York, 1979), p. 62.

9. "Key Issues in US-USSR Scientific Exchanges and Technology Transfer," Subcommittee on Science Research and Technology of the Committee on Science and Technology, US House of Representatives (November 1979), p. 5.

10. Aviat. Week Space Technol., p. 33 (June 15, 1981).

11. Sherry Rae McNeal, Proc. Am. Astronaut. Soc., San Francisco, July 20-21, 1979, p. 129.

12. "United States and Soviet Progress in Space," report for the Subcommittee on Space Science and Applications, US House of Representatives (April 1980), p. 42.

\section{APPENDIX}

\section{RATIONALE}

It is not our intent to make "the case for space" here, but we believe the US space program is necessary for the following reasons.

- The absence of explicit international agreements for open skies and ground inspection makes the world dangerous for everyone. One of the greatest safeguards against miscalculation by the major powers is precise information from space about military and related activities all over the Earth. This is the cornerstone for arms control agreements.

- A society develops according to its expectutions of the future. Those who view the future as a clash of the Third World's rising hopes with the Earth's finite resources argue that Western values as we know them are threatened. Sooner or later, they point out, a Zero Sum world will require a totalitarian authority to distribute goods and services, control population growth, and enforce pollution standards. This view could become a self-fulfilling prophecy.
On the other hand, the certainty that democracy can exist indefinitely is the view of those who see the future as a challenge to our innovative and creative abilities. This view advocates growth to increase the wealth of the world and technology to escape the limits to growth. Consequently, mankind will eventually need the extraterrestrial environment to develop both resources and manufacturing techniques. Therefore, they argue, inhabiting space is inevitable and the sooner we start the sooner we will reap the benefits. Adopted by enough people, this alternative view could become a self-fulfilling prophecy.

Ultimately, our imagination and the gifts of the universe are the only real limits to growth.

- Space is a harsh frontier that imposes new standards of excellence on those who would master it. A society that forges its leaders in such unforgiving environments has a survival advantage in the competition of groups and against catastrophes of nature. We must move into space quickly so that this opportunity cannot be denied to us by others. 
- The profit motive is the most effective and efficient mechanism for opening a new frontier. Substitutes like government regulation, military imperative, or ideological enthusiasm prove too unproductive, too expensive, or too transient. The US "engines of commerce" can minimize man's costs of moving into space.
- The:United States Government can give a șense of national purpose to its people by focusing its space program on a goal of progress for mankind.: We believe the space venture will give the United States a new vision and the world a new hope. 

Printed in the United States of America
Available from

National Technical Information Service

US Department of Commerce

5285 Port Royal Road

Springfield, VA 22161

Microfiche $\$ 3.50$ (A01)

NTIS

Price Code Page Range

NTIS

Price Code

Price Code Page Range Price

$301-325$

$301-325$

$151-175 \quad \$ 11.00$

176.200

201-225

226-250

12.00

A08

13.00

A 10

$326-350$

$351-375$

$376-400$

A12 $\quad 401-425$

276-300

15.00

$426-450$

Price

18.00
19.00

19.00
20.00

21.00

22.00

A14

A15

SU1-525

$541-525$
$526-550$

A $18 \quad 551.575$

$576-600$

601-up

Domestic

NTIS

Price Price Code

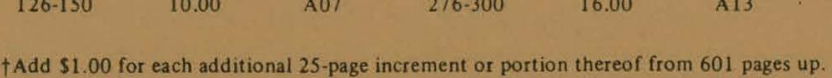




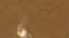

Los Alaños 